\title{
Non-Clear Cell Renal Carcinomas: About 23 Cases Experience of the Medical Oncology Department of the Hassan II Hospital in Fez, Morocco
}

\author{
Lamyae Nouiakh*, Karima Oualla, Imane Ouafki, Soumia Berrad, Hayat Erraichi, \\ Lamiae Amaadour, Zineb Benbrahim, Samia Arifi, Nawfel Mellas
}

Department of Medical Oncology, Hassan II University Hospital, Fes, Morocco

Email: *nouiakhlamyae@gmail.com

How to cite this paper: Nouiakh, L., Oualla, K., Ouafki, I., Berrad, S., Erraichi, H., Amaadour, L., Benbrahim, Z., Arifi, S. and Mellas, N. (2021) Non-Clear Cell Renal Carcinomas: About 23 Cases Experience of the Medical Oncology Department of the Hassan II Hospital in Fez, Morocco. Open Journal of Nephrology, 11, 34-42. https://doi.org/10.4236/ojneph.2021.111004

Received: January 21, 2021

Accepted: March 2, 2021

Published: March 5, 2021

Copyright $\odot 2021$ by author(s) and Scientific Research Publishing Inc. This work is licensed under the Creative Commons Attribution International License (CC BY 4.0).

http://creativecommons.org/licenses/by/4.0/

\begin{abstract}
Background: Non-clear cell renal cell carcinomas represent a very rare and heterogeneous variety of kidney cancer. The aim of this study is to describe the main epidemiological, clinical, paraclinical, histological and therapeutic characteristics of these cancers. Methods: A descriptive retrospective study was conducted in the Medical Oncology Department of the Hassan II Hospital in Fez, collecting 23 patients with these tumors during the period from January 2008 to January 2020. The statistical analysis is made by the SPSS software version 23. Survival was calculated by the Kaplan-Meier method. Results: The average age of the patients was 57.4 years. The sex ratio M/F was 1.3. The main risk factor was smoking $(\mathrm{n}=10)$. The most common symptom was low back pain $(n=23) .17$ patients were metastatic, while 6 patients had localized disease. The most common histological type was papillary carcinoma $(n=12)$. Patients with localized disease have undergone an extended total nephrectomy. After a median follow-up of 145 months, the median of recurrence-free survival was 48 months and that of overall survival was 150 months. In a metastatic situation, 16 patients had received systemic treatment, of which 13 patients had received sunitinib, 2 patients pazaopanib and only one patient received everolimus. After a median follow-up of 20 months, the median of progression-free survival was 5 months and that of overall survival was 9 months. Conclusion: At the present time, there is no therapeutic standard for the management of patients with these tumors. Surgery for people with localized or locally advanced disease remains the initial and most important approach. For patients with advanced disease, a clinical trial should be considered.
\end{abstract}


Keywords

Kidney, Non-Clear Cell Carcinoma, Targeted Therapy

\section{Background}

Kidney cancer is a rare pathology; renal cell carcinoma with clear cells represents the most common histological type with a percentage of $75 \%$ [1]. Non-clear cell carcinomas are a heterogeneous group of tumors, accounting for $25 \%$ of all kidney cancers [2]. They include papillary carcinomas (10\% - 15\%), chromophobic carcinomas (5\%), unclassified carcinomas (5\%), and collecting duct and medullary carcinomas $(<5 \%)$ [3]. In recent years, the advent of targeted therapies (tyrosine kinase inhibitors and mTOR inhibitors) and immune checkpoint inhibitors has changed the prognosis of kidney cancer; however, these therapies are limited to clear cell histology because the majority of clinical trials conducted to date have excluded patients with non-clear cell histology [4]. There are a limited number of clinical trials treating exclusively nnRCC. Therefore, data on the efficacy of targeted therapies in NCCRC have demonstrated moderate activity in terms of response rate and survival (progression free survival (PFS) and overall survival (OS)). The objective of this study is to determine the main epidemiological, clinical, paraclinical, histological and therapeutic aspects of these tumors in order to compare them with those reported in the literature.

\section{Methods}

A descriptive retrospective study was conducted at the medical oncology service of the Hassan II University Hospital in Fez, bringing together 23 patients with non-clear cell renal carcinoma during the period from January 2008 to January 2020. We included all patients with the diagnosis of renal cancer with non-clear cell histological evidence, and who were treated in the medical oncology department. The statistical analysis was carried out made by the SPSS version 23 software, the qualitative variables were expressed as frequency and percentage and the quantitative variables were expressed as median, mean and standard deviation. Survival was calculated by the Kaplan-Meier method.

\section{Results}

\subsection{Epidemiological Data}

Between January 2008 and January 2020, 23 patients with non-clear cell renal cell carcinoma in the medical oncology department of CHU Hassan II in Fez were included. The mean age of patients at diagnosis was 57.4 years with age ranges ranging from 35 to 88 years. There was a slight male predominance (sex ratio $\mathrm{M} / \mathrm{F}$ was 1.3 ). The risk factors for kidney cancer found in our study were smoking in 10 patients and obesity in 6 patients. No history of renal failure, hemodialysis, renal transplant or occupational exposure has been reported, and no 
case of familial renal cell carcinoma has been reported.

\subsection{Clinical and Paraclinical Data}

18 patients were in good general condition at the time of diagnosis (PS at 1). The most common symptom was low back pain reported by all patients, followed by hematuria in 6 patients. Following this clinical symptomatology, all patients had undergone a renal ultrasound followed by a CT scan.

At the end of this assessment, 17 patients were metastatic from the outset, while 6 patients had localized disease. The elective sites of metastases in order of frequency were: lung $(n=17)$, lymph node $(n=11)$, bone $(n=11)$, liver $(n=6)$ and brain $(n=1)$.

\subsection{Histological Data}

The most common histologic type was papillary carcinoma $(n=12)$, followed by renal carcinoma $(n=6)$, then chromophobic carcinoma $(n=4)$ and finally sarcomatoid carcinoma observed in a single patient.

\subsection{Therapeutic Data}

An enlarged total nephrectomy was performed in all patients with localized disease.

After a median follow-up of 145 months, the median recurrence-free survival was 48 months and that of overall survival was 150 months.

In a metastatic situation, whether onset or relapse after curative surgical treatment, 16 patients had received systemic treatment, of which 13 patients had received sunitinib, 2 patients received pazaopanib and only one patient had everolimus (Table 1).

Table 1. Patient characteristics.

\begin{tabular}{ccc}
\hline Characteristics & Number (\%) \\
\hline \multirow{2}{*}{ Gender } & Female & $13(57)$ \\
& Smoking & $10(43)$ \\
\hline \multirow{2}{*}{ Risk factors } & Obesity & $10(43)$ \\
& Renal failure, hemodialysis & $6(26)$ \\
& Kidney transplant & $0(0)$ \\
& Professional exposure & $0(0)$ \\
& Family cases & $0(0)$ \\
Circumstances of discovery & Back pain & $0(0)$ \\
& Haematuria & $23(100)$ \\
& Lucky find & $6(2)$ \\
Performance status (PS) & $1-2$ & $0(0)$ \\
& 3 & $18(78)$ \\
& & $5(22)$
\end{tabular}


Continued

\begin{tabular}{ccc}
\hline Stage & Localized & $6(26)$ \\
& Metastatic & $17(74)$ \\
\hline Letastatic sites & Lymph nodes & $17(74)$ \\
& Bone & $11(48)$ \\
& Liver & $11(48)$ \\
Histological type & Brain & $6(26)$ \\
& Papillary carcinoma & $1(4)$ \\
\hline Renal adenocarcinoma & $12(52)$ \\
First line treatment & Chromophobic carcinoma & $6(26)$ \\
& Sarcomatoid carcinoma & $4(18)$ \\
\hline Systemic treatment & Enlarged nephrectomy & $1(4)$ \\
& Systemic treatment & $6(26)$ \\
& Palliative care & $12(52)$ \\
& SUNITINIB & $5(22)$ \\
\hline & PAZOPANIB & $13(81)$ \\
\hline & EVEROLIMUS & $2(13)$ \\
\hline & & $1(6)$ \\
\hline
\end{tabular}

The main undesirable effects that were induced by the targeted therapies: haematological toxicity $(n=9)$, fatigue $(n=8)$, mucositis $(n=5)$, hand-foot syndrome $(\mathrm{n}=3)$. Vomiting and nausea occurred in 2 patients. Diarrhea has been reported in patients receiving pazopanib. High blood pressure was observed in 4 patients who were on sunitinib.

After a median follow-up of 20 months, the median progression-free survival was 5 months and that of overall survival was 9 months.

\section{Discussion}

In our study, renal non-clear cell carcinomas were more common in males. The main risk factors were smoking and obesity. The clinical symptomatology was non-specific, dominated by low back pain. Most of the patients were in good general performance status at the time of diagnosis. The majority of cases diagnosed were metastatic to begin with. The most common metastatic sites were the lung, bone and lymph nodes. The non-clear cell carcinomas found in our study were papillary carcinoma, adenocarcinoma, chromophobic carcinoma and sarcomatoid carcinoma. Sunitinib was the most widely used first-line therapy. The main side effects observed with targeted therapies were fatigue, mucositis and haematological complications. The median overall survival was 9 months after a median follow-up of 20 months in metastatic patients and it was 150 months in those with localized disease.

Non-clear cell renal carcinomas (NCCRC) are heterogeneous histologic types 
of tumors; they represent $25 \%$ of all renal cancers [2]. In our series, NCCRCs represented $26 \%$ of all renal cancers diagnosed during the study period. NCCRCs most commonly occur in men with a sex ratio of 2 men to 1 woman [5]. This rate is close to that found in our series (sex ratio M/F of 1.4). The clinical signs are nonspecific and renal carcinomas, in particular NCCRCs, are increasingly revealed by chance thanks to improved imaging techniques. In our study, no cases were incidentally discovered because the majority of cases had metastatic disease at the time of diagnosis.

The definitive diagnosis remains the histological examination; it is made either on a biopsy sample or on an excisional piece. On the anatomopathological level, several histological varieties are distinguished: the first variety is represented by papillary carcinomas (PC); it is the most common form of NCCRC, it accounts for $10 \%$ to $15 \%$ of renal cancers [3], this type of tumor starts from the proximal convoluted tube of the nephron [6]. There are 2 histological subtypes, PC type 1 and type 2 based on distinct morphological and molecular characteristics defined by alterations in the c-Met oncogene (type 1) or the fumarate hydratase gene (type 2) [7] [8]. PC type 2 represents the most aggressive form with a significant risk of relapse and death compared to that of type 1 . The second histological type is represented by chromophobic carcinomas. These tumors are rarer, they represent $5 \%$ of renal cancer cases [3], and they originate from intercalary cells of the distal nephron [6]. They preferentially affect the female sex at a young age [9]. It has been shown through studies that obesity and tobacco consumption promotes the occurrence of this type of cancer (10]. One of the peculiarities of these carcinomas is the rarity of metastatic forms [11]. Their prognosis is generally favorable because they are generally mild tumors, of limited stage and of low grade. Collector duct carcinomas and medullary carcinomas are extremely rare and very aggressive tumors, characterized by a fatal and poor prognosis because they often present early metastases, they represent $1 \%$ to $2 \%$ of all renal cancers [3], these tumors originate from the distal tubule [6] and share similarities with urothelial carcinomas of the upper urinary tract, which implies the use of platinating agents in their therapeutic approach [12]. Another rare histological type of NCCRC is the unclassified carcinoma, the latter represents approximately $5 \%$ of renal cancers [3], this type will be evoked when the carcinoma does not correspond to the macroscopic and histological criteria of the other carcinomas and it is of pejorative prognosis. There is another type of carcinoma associated with the translocation [13], these carcinomas are secondary to chromosomal translocations of the transcription factor genes in particular the transcription factor E3 (TFE3), the transcription factor EB (TFEB) and MITF [14]. They most often occur in children and young adults. Finally, the sarcomatoid variant is often included in NCCRCs; however, it is not considered a distinct histologic type and can be found with any histologic type [15] [16], its presence is generally associated with an appalling prognosis [17]. In our study, the results were almost similar to those reported in the literature in terms of incidence; the most common histological type was papillary carcinoma (52\%), 
Table 2. Randomized controlled studies conducted in the treatment of patients with NCCRC.

\begin{tabular}{|c|c|c|c|c|c|c|c|}
\hline Study & Protocol & Number & Line & $\begin{array}{c}\text { Median } \\
\text { progression-free } \\
\text { survival (months) }\end{array}$ & $\begin{array}{c}\text { Hazard ratio } \\
\text { (95\% confidence } \\
\text { interval) }\end{array}$ & $\begin{array}{c}\text { Median overall } \\
\text { survival (months) }\end{array}$ & $\begin{array}{c}\text { Hazard ratio } \\
\text { (95\% confidence } \\
\text { interval) }\end{array}$ \\
\hline \multirow{3}{*}{$\begin{array}{c}\text { ASPEN } \\
\text { [19] }\end{array}$} & Everolimus & 57 & 1 & 5.6 & \multirow{3}{*}{$1.41(1.03-1.92)$} & 13.2 & \multirow{3}{*}{$1.12(0.7-2.1)$} \\
\hline & vs & & & & & & \\
\hline & Sunitinib & 51 & 1 & 8.3 & & 31.5 & \\
\hline \multirow{3}{*}{$\begin{array}{l}\text { RECORD } \\
{[20]}\end{array}$} & Everolimus & 31 & 1 & 7.9 & \multirow{3}{*}{$1.4(1.2-1.8)$} & \multirow{3}{*}{ - } & \multirow{3}{*}{-} \\
\hline & vs & & & & & & \\
\hline & Sunitinib & 35 & 1 & 10.7 & & & \\
\hline \multirow{3}{*}{$\begin{array}{c}\text { ESPN } \\
{[21]}\end{array}$} & Everolimus & 35 & 1 & 4.1 & \multirow{3}{*}{ - } & 14.9 & \multirow{3}{*}{-} \\
\hline & vs & & & & & & \\
\hline & Sunitinib & 33 & 1 & 6.1 & & 16.2 & \\
\hline \multirow{3}{*}{$\begin{array}{c}\text { ARCC } \\
{[22]}\end{array}$} & Interferon- $\alpha$ & 36 & 1 & 1.8 & \multirow{3}{*}{$0.38(0.23-0.62)$} & 4.3 & \multirow{3}{*}{$0.49(0.29-0.85)$} \\
\hline & vs & & & & & & \\
\hline & Temsirolimus & 37 & 1 & 7.0 & & 11.6 & \\
\hline \multirow{3}{*}{$\begin{array}{c}\text { SWOG } \\
{[23]}\end{array}$} & Tivantinib & 25 & 1 et 2 & 2 & \multirow{3}{*}{ - } & 10.3 & \multirow{3}{*}{ - } \\
\hline & vs & & & & & & \\
\hline & Tivantinib + erlotinib & 25 & 1 et 2 & 3.9 & & 11.3 & \\
\hline
\end{tabular}

followed by renal carcinoma (26\%), then chromophobic carcinoma (18\%) and finally sarcomatoid carcinoma in $4 \%$ of cases.

Therapeutically; for metastatic forms, there is no consensus on the best treatment to use as a first-line treatment due to the rarity of these tumors, the recommendations of learned societies require the inclusion of patients with these tumors in clinical trials [18]. Several studies evaluated the effectiveness of tyrosine kinase inhibitors (TKIs) and mTOR pathway inhibitors in the treatment of patients with locally advanced or metastatic CRNCC, these trials included 5 randomized controlled studies [19] [20] [21] [22] [23] (Table 2) 21 phase II single-arm trials and 4 prospective meta-analyzes testing 22 systemic treatments for a total of 2134 patients. Overall, the treatment results were modest and were inferior to those found in clear cell renal cancers. In our study, 16 patients received systemic treatment, of which 13 patients received sunitinib, 2 patients received pazaopanib and only one patient received everolimus.

In the absence of effective systemic treatment, cytoreductive nephrectomy (CN) plays an important role in the management of NCCRCs. Although the majority of studies, have been performed in patients with clear cell carcinoma [24] [25]. Aizer and his colleagues studied the role of cytoreductive nephrectomy in NCCRCs and found a survival benefit of $\mathrm{CN}$ in patients with these tumors [26].

\section{Conclusion}

At present, there is no therapeutic standard for the treatment of patients with NCCRC. Although inhibition of the mTOR and VEGF signaling pathways may have a clinical benefit, it is often marginal and the prognosis remains poor. Sur- 
gery for people with localized or locally advanced disease remains the initial and most important approach. For patients with advanced disease, a clinical trial should be considered.

\section{Funding}

The authors received no specific funding for this study.

\section{Conflicts of Interest}

The authors declare that they have no competing interests.

\section{References}

[1] Ferlay, J., Soerjomataram, I., Dikshit, R., et al. (2015) Cancer Incidence and Mortality Worldwide: Sources, Methods and Major Patterns in GLOBOCAN 2012. International Journal of Cancer, 136, E359-E386. https://doi.org/10.1002/ijc.29210

[2] Cohen, H.T. and McGovern, F.J. (2005) Renal-Cell Carcinoma. The New England Journal of Medicine, 353, 2477-2490. https://doi.org/10.1056/NEJMra043172

[3] Reuter, V.E. (2006) The Pathology of Renal Epithelial Neoplasms. Seminars in Oncology, 33, 534-543. https://doi.org/10.1053/j.seminoncol.2006.06.009

[4] Pal, S.K. and Choueiri, T.K. (2014) Systemic Therapies for Metastatic Renal Cell Carcinoma of Variant Histology. In: Tannir, N.M., Ed., Renal Cell Carcinoma, Oxford American Oncology Library, New York, 109-116.

[5] Mejean, A., Andre, M., Doublet, J.D., et al. (2004) Tumeurs du rein. Progrès en Urologie, 14, 999-1035.

[6] Kovacs, G., Akhtar, M., Beckwith, B.J., et al. (1997) The Heidelberg Classification of Renal Cell Tumours. The Journal of Pathology, 183, 131-310. https://doi.org/10.1002/(SICI)1096-9896(199710)183:2<131::AID-PATH931>3.0.C $\underline{\mathrm{O} ; 2-\mathrm{G}}$

[7] Delahunt, B. and Eble, J.N. (1997) Papillary Renal Cell Carcinoma: A Clinicopathologic and Immunohistochemical Study of 105 Tumors. Modern Pathology, 10, 537-544.

[8] Yang, X.J., Tan, M.H., Kim, H.L., et al. (2005) A Molecular Classification of Papillary Renal Cell Carcinoma. Cancer Research, 65, 5628-5637. https://doi.org/10.1158/0008-5472.CAN-05-0533

[9] Gillett, M.D., Cheville, J.C., Karnes, R.J., et al. (2005) Comparison of Presentation and Outcome for Patients 18 to 40 and 60 to 70 Years Old with Solid Renal Masses. Journal of Urology, 173, 1893-1896. https://doi.org/10.1097/01.ju.0000158157.57981.80

[10] Purdue, M.P., Moore, L.E., Merino, M.J., et al. (2013) An Investigation of Risk Factors for Renal Cell Carcinoma by Histologic Subtype in Two Case-Control Studies. International Journal of Cancer, 132, 2640-2647. https://doi.org/10.1002/ijc.27934

[11] Cheville, J.C., Lohse, C.M., Zincke, H., Weaver, A.L. and Blute, M.L. (2003) Comparisons of Outcome and Prognostic Features among Histologic Subtypes of Renal Cell Carcinoma. The American Journal of Surgical Pathology, 27, 612-624. https://doi.org/10.1097/00000478-200305000-00005

[12] Kwon, K.A., Oh, S.Y., Kim, H.Y., et al. (2014) Clinical Features and Treatment of Collecting Duct Carcinoma of the Kidney from the Korean Cancer Study Group 
Genitourinary and Gynecology Cancer Committee. Cancer Research and Treatment, 46, 141-147. https://doi.org/10.4143/crt.2014.46.2.141

[13] Sidhar, S.K., Clark, J., Gill, S., et al. (1996) The t(X;1)(p11.2;q21.2) Translocation in Papillary Renal Cell Carcinoma Fuses a Novel Gene PRCC to the TFE3 Transcription Factor Gene. Human Molecular Genetics, 5, 1333-1338.

https://doi.org/10.1093/hmg/5.9.1333

[14] Linehan, W.M., Pinto, P.A., Bratslavsky, G., et al. (2009) Hereditary Kidney Cancer: Unique Opportunity for Disease-Based Therapy. Cancer, 115, 2252-2261. https://doi.org/10.1002/cncr.24230

[15] Zisman, A., Chao, D.H., Pantuck, A.J., et al. (2002) Unclassified Renal Cell Carcinoma: Clinical Features and Prognostic Impact of a New Histological Subtype. Journal of Urology, 168, 950-955. https://doi.org/10.1016/S0022-5347(05)64549-1

[16] Moch, H., Cubilla, A.L., Humphrey, P.A., Reuter, V.E. and Ulbright, T.M. (2016) The 2016 WHO Classification of Tumours of the Urinary System and Male Genital Organs Part A: Renal, Penile, and Testicular Tumours. European Urology, 70, 93-105. https://doi.org/10.1016/j.eururo.2016.02.029

[17] Comperat, E.V., Vasiliu, V., Ferlicot, S., Camparo, P., Sibony, M. and Vieillefond, A. (2005) Les cancers du rein: Nouvelle classification. Annales de Pathologie, 25, 117-133. https://doi.org/10.1016/S0242-6498(05)86175-9

[18] Motzer, R.J., Agarwal, N., Beard, C., et al. (2011) NCCN Clinical Practice Guidelines in Oncology for Kidney Cancer. Journal of the National Comprehensive Cancer Network, 9, 960-977. https://doi.org/10.6004/jnccn.2011.0082

[19] Armstrong, A.J., Halabi, S., Eisen, T., et al. (2016) Everolimus versus Sunitinib for Patients with Metastatic Non-Clear Cell Renal Cell Carcinoma (ASPEN): A Multicentre, Open-Label, Randomised Phase 2 Trial. The Lancet Oncology, 17, 378-388. https://doi.org/10.1016/S1470-2045(15)00515-X

[20] Knox, J.J., et al. (2017) Final Overall Survival Analysis for the Phase II RECORD-3 Study of First-Line Everolimus Followed by Sunitinib versus First-Line Sunitinib Followed by Everolimus in Metastatic RCC. Annals of Oncology, 28, 1339-1345. https://doi.org/10.1093/annonc/mdx075

[21] Tannir, N.M., et al. (2016) Everolimus versus Sunitinib Prospective Evaluation in Metastatic Non-Clear Cell Renal Cell Carcinoma (ESPN): A Randomized Multicenter Phase 2 Trial. European Urology, 69, 866-874. https://doi.org/10.1016/j.eururo.2015.10.049

[22] Hudes, G., Carducci, M., et al. (2007) Temsirolimus, Interferon Alfa, or Both for Advanced Renal-Cell Carcinoma. The New England Journal of Medicine, 356, 2271-2281. https://doi.org/10.1056/NEJMoa066838

[23] Twardowski, P.W., et al. (2017) Parallel (Randomized) Phase II Evaluation of Tivantinib (ARQ197) and Tivantinib in Combination with Erlotinib in Papillary Renal Cell Carcinoma: SWOG S1107. Kidney Cancer, 1, 123-132. https://doi.org/10.3233/KCA-170018

[24] Flanigan, R.C., Salmon, S.E., Blumenstein, B.A., et al. (2001) Nephrectomy Followed by Interferon alfa- $2 \mathrm{~b}$ Compared with Interferon alfa- $2 \mathrm{~b}$ Alone for Metastatic Renal-Cell Cancer. The New England Journal of Medicine, 345, 1655-1659. https://doi.org/10.1056/NEJMoa003013

[25] Mickisch, G.H., Garin, A., van Poppel, H., de Prijck, L., Sylvester, R., European Organisation for Research and Treatment of Cancer (EORTC) Genitourinary Group, et al. (2001) Radical Nephrectomy plus Interferon-Alfa-Based Immunotherapy Compared with Interferon Alfa Alone in Metastatic Renal-Cell Carcinoma: A Ran- 
domised Trial. The Lancet, 358, 966-970.

https://doi.org/10.1016/S0140-6736(01)06103-7

[26] Aizer, A.A., Urun, Y., McKay, R.R., Kibel, A., Nguyen, P.L. and Choueiri, T.K. (2013) Cytoreductive Nephrectomy in Patients with Metastatic Non-Clear Cell Renal Cell Carcinoma. BJU International, 113, 67-74.

https://doi.org/10.1111/bju.12442 